\title{
Fabrication of Intrinsic Zinc Oxide-Coated, Aluminium-Doped Zinc Oxide Nanorod Array-Based Ultraviolet Photoconductive Sensors
}

\author{
M.H. Mamat ${ }^{1,2, a^{*}}$, M.F. Malek ${ }^{1, b}$, N.N. Hafizah ${ }^{2, c}$, N.D. Md $\operatorname{Sin}^{1, d}$, I. Saurdi ${ }^{1, e}$,

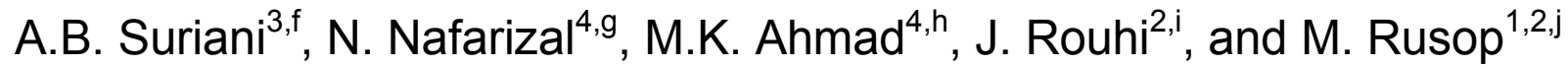 \\ ${ }^{1}$ NANO-ElecTronic Centre, Faculty of Electrical Engineering, Universiti Teknologi MARA, 40450 \\ Shah Alam, Selangor, Malaysia. \\ ${ }^{2}$ NANO-SciTech Centre, Institute of Science, Universiti Teknologi MARA, 40450 Shah Alam, \\ Selangor, Malaysia. \\ ${ }^{3}$ Department of Physics, Faculty of Science and Mathematics, Universiti Pendidikan Sultan Idris \\ (UPSI), 35900 Tanjung Malim, Perak, Malaysia \\ ${ }^{4}$ Microelectronic and Nanotechnology - Shamsuddin Research Centre (MiNT-SRC), Faculty of \\ Electrical and Electronic Engineering, Universiti Tun Hussein Onn Malaysia, 86400 Batu Pahat, \\ Johor, Malaysia \\ amhmamat@salam.uitm.edu.my, bfirz_solarzelle@yahoo.com, ${ }^{\mathrm{c} n}$.noor_hafizah@yahoo.com, \\ dnordiyana86@yahoo.com, 'saurdy788@gmail.com, absuriani@yahoo.com, ${ }^{\mathrm{f}}$ nafa@uthm.edu.my, \\ hakhairul@uthm.edu.my, jalalrouhi@gmail.com, 'rusop@salam.uitm.edu.my
}

Keywords: ZnO nanorod arrays; Coating; Sonicated Sol-Gel Immersion; RF magnetron sputtering; UV photoconductive sensors

\begin{abstract}
Fabrication and performance of metal-semiconductor-metal (MSM)-type intrinsic zinc oxide $(\mathrm{ZnO})$-coated, aluminium ( $\mathrm{Al}$ )-doped $\mathrm{ZnO}$ nanorod array-based ultraviolet photoconductive sensors were reported and discussed. The Al-doped $\mathrm{ZnO}$ nanorod arrays were prepared using sonicated sol-gel immersion method. The coating process of intrinsic $\mathrm{ZnO}$ onto Al-doped $\mathrm{ZnO}$ nanorod arrays was performed using radio-frequency (RF) magnetron sputtering at different deposition times varying from 0 to $10 \mathrm{~min}$. We observed that responsivity of the sensors decreased with increasing intrinsic $\mathrm{ZnO}$ deposition time, decreasing from $4.81 \mathrm{~A} / \mathrm{W}$ without coating to 1.37 $\mathrm{A} / \mathrm{W}$ after $10 \mathrm{~min}$ of coating. Interestingly, the sensitivity of the sensors improved with intrinsic $\mathrm{ZnO}$ coating, having a maximum value of 19.0 after 1 min coating.
\end{abstract}

\section{Introduction}

Nanostructured zinc oxide $(\mathrm{ZnO})$ is one of the most promising semiconductor materials for applications in solar cells, and various sensors [1-5]. Particularly in ultraviolet (UV) sensor application, much attention has been paid to nanostructured $\mathrm{ZnO}$ because of chemical stability, large surface area, good oxidation resistibility, great biocompatibility, and high conductivity. Currently, major investigations have focused on the development of one-dimensional (1D) zinc oxide $(\mathrm{ZnO})$ nanostructures, such as nanorod arrays, which have several advantages for ultraviolet (UV) photoconductive sensor applications including wide bandgap, high surface area, and carrier confinement in two dimensions that could improve the sensor performance. The UV sensing properties of $\mathrm{ZnO}$ nanorod arrays are mainly dependent on their preparation methods, alignments, sizes, and surface conditions [4, 6-8]. In this study, we fabricated UV photoconductive sensor aluminium (Al)-doped $\mathrm{ZnO}$ nanorod arrays, which have been decorated with sputtered intrinsic $\mathrm{ZnO}$ at different deposition time and their performances were investigated. Interestingly, the sensitivity and the response of the devices improved with the addition of sputtered intrinsic $\mathrm{ZnO}$ on the nanorod surface. 


\section{Experimental Procedure}

Al-doped $\mathrm{ZnO}$ nanorod arrays were grown on a glass substrate coated with an Al-doped $\mathrm{ZnO}$ seed layer using a sonicated sol-gel immersion method [9]. The Al-doped $\mathrm{ZnO}$ thin film, which was used as a seed layer, was prepared on the glass substrate using sol-gel spin-coating [10]. The Aldoped $\mathrm{ZnO}$ nanorod arrays were grown on the seed-layer-coated glass substrate using aqueous solutions of $0.1 \mathrm{M}$ zinc nitrate hexahydrate $\left(\mathrm{Zn}\left(\mathrm{NO}_{3}\right)_{2} \cdot 6 \mathrm{H}_{2} \mathrm{O} ; 98 \%\right.$ purity; Systerm), $0.1 \mathrm{M}$ hexamethylenetetramine (HMT; $\mathrm{C}_{6} \mathrm{H}_{12} \mathrm{~N}_{4} ; 99 \%$ purity; Aldrich), and $0.001 \mathrm{M}$ aluminium nitrate nonahydrate $\left(\mathrm{Al}\left(\mathrm{NO}_{3}\right)_{3} \cdot 9 \mathrm{H}_{2} \mathrm{O} ; 98 \%\right.$ purity; Analar). These reagents were dissolved and reacted in a beaker filled with deionised (DI) water using an ultrasonic water bath for 30 min (Hwasin Technology Powersonic 405; $40 \mathrm{kHz}$ ). The temperature for the sonication process was $50^{\circ} \mathrm{C}$. The solution was then stirred and aged for $3 \mathrm{~h}$ at room temperature. The resulting solution was poured into vessels with volume capacities of $100 \mathrm{ml}$, into which the seed-layer-coated glass substrates were placed on the bottom. Next, the sealed vessels were immersed in a hot water bath at $95{ }^{\circ} \mathrm{C}$. The samples were immersed for $50 \mathrm{~min}$. The nanorods deposited on the substrates were rinsed with DI water and dried in a furnace at $150{ }^{\circ} \mathrm{C}$ for $10 \mathrm{~min}$. Then, Al-doped $\mathrm{ZnO}$ nanorod arrays were coated with intrinsic $\mathrm{ZnO}$ (4-inch $\mathrm{ZnO}$ target: purity $99.99 \%$; Process Materials Inc.) using radiofrequency (RF) magnetron sputtering (SNTEK) at an RF power of $50 \mathrm{~W}$, before annealing in air at $500{ }^{\circ} \mathrm{C}$ for $1 \mathrm{~h}$. The coating process was performed after $10 \mathrm{~min}$ of pre-coating in $45 \mathrm{sccm}$ argon (Ar) and $20 \mathrm{sccm}$ oxygen $\left(\mathrm{O}_{2}\right)$ which flowed at a deposition pressure of $0.67 \mathrm{~Pa}$ with varying deposition times of 1,5 , and $10 \mathrm{~min}$. The coated intrinsic layer thickness was estimated as 5, 18, and $35 \mathrm{~nm}$, respectively. Next, 60-nm-thick Al contacts were deposited on the nanorod array films using a thermal evaporator to produce a metal-semiconductor-metal (MSM)-type UV photoconductive sensor. The deposition of metal contacts was performed at a chamber pressure of 4 $\times 10^{-4} \mathrm{~Pa}$. The separation between the metal contacts was fixed at $2.00 \mathrm{~mm}$ for all samples using a metal mask.

The surface morphology and cross-sectional images of the samples were taken with a fieldemission scanning electron microscopy (FESEM; JEOL; Model: JSM-7600F). The current-voltage (I-V) characteristics of the UV photoconductive sensors were investigated using a two-probe I-V measurement system (Keithley; Model: 2400). The UV photoresponse measurements of the fabricated sensors were taken using a UV photocurrent measurement system (Keithley; Model: 2400 ) operating at $365 \mathrm{~nm}$ with a power density of $750 \mu \mathrm{W} / \mathrm{cm} 2$ and a bias voltage of $10 \mathrm{~V}$.

\section{Results and Discussion}

The FESEM images of samples coated for 0 (uncoated), 1 and $10 \mathrm{~min}$ are shown in Figures 1(a), 1(b) and 1(c), respectively. The image in Figure 1(a) shows that the nanorods grew uniformly on the seed layer substrate with an average diameter of $61 \mathrm{~nm}$. When the nanorods were coated with sputtered intrinsic $\mathrm{ZnO}$ for $1 \mathrm{~min}$, no significant change in morphology was observed, as shown in Figure 1(b). However, the surface of nanorods was modified when the nanorod were coated with sputtered intrinsic $\mathrm{ZnO}$ for $10 \mathrm{~min}$, which can be seen in Figure 1(c). The image in Figure 1(c) shows that the surface of nanorods became rough with intrinsic coating for $10 \mathrm{~min}$ as a result from coated intrinsic $\mathrm{ZnO}$ particles through sputtering process. These images in Figures 1 show that the $\mathrm{ZnO}$ particles are clearly observed for intrinsic $\mathrm{ZnO}$ coatings deposited for longer periods of time. These images also reveal that sputtered, intrinsic $\mathrm{ZnO}$ were uniformly deposited on surface of the nanorod arrays.

Figure 2 depicts I-V curves at different deposition times. The I-V curves indicate that the Al metal connections form good ohmic contacts with both uncoated and sputtered, intrinsic ZnOcoated Al-doped $\mathrm{ZnO}$ nanorod arrays. The spectra reveal that the current intensity with respect to the voltage decreases when the deposition time of the intrinsic $\mathrm{ZnO}$ layer was increased. The resistance of the samples was calculated to be $0.16,0.27,0.31$, and $0.47 \mathrm{M} \Omega$ after the Al-doped $\mathrm{ZnO}$ nanorod arrays were coated with intrinsic $\mathrm{ZnO}$ at deposition times of 0 (uncoated), 1, 5, and 10 
min, respectively. The increase in resistance indicates that a thicker, lower-conductivity layer is deposited onto the nanorod surface as deposition time increases [7].

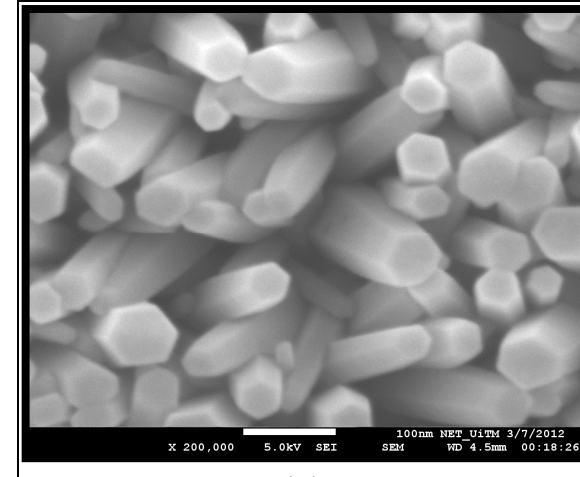

(a)

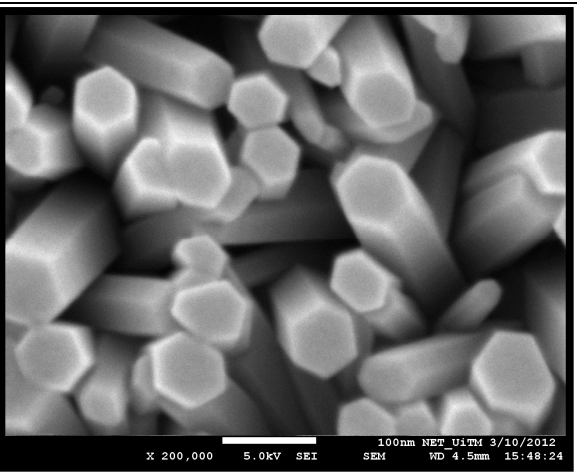

(b)

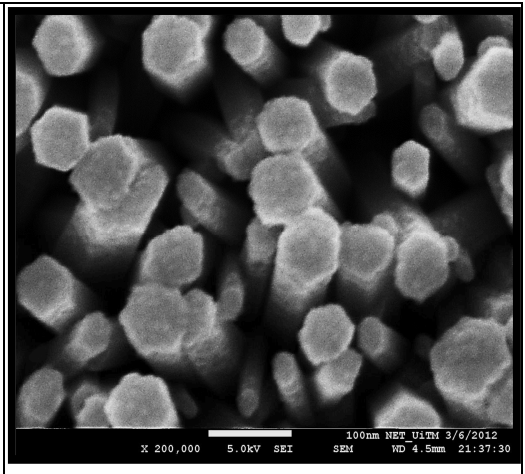

(c)

Figure 1, The FESEM Images of Al-Doped ZnO Nanorod Arrays Prepared at an Immersion Time of 50 min and Coated with Intrinsic ZnO at Deposition Times of (a) 0, (b) 1, and (c) $10 \mathrm{~min}$.

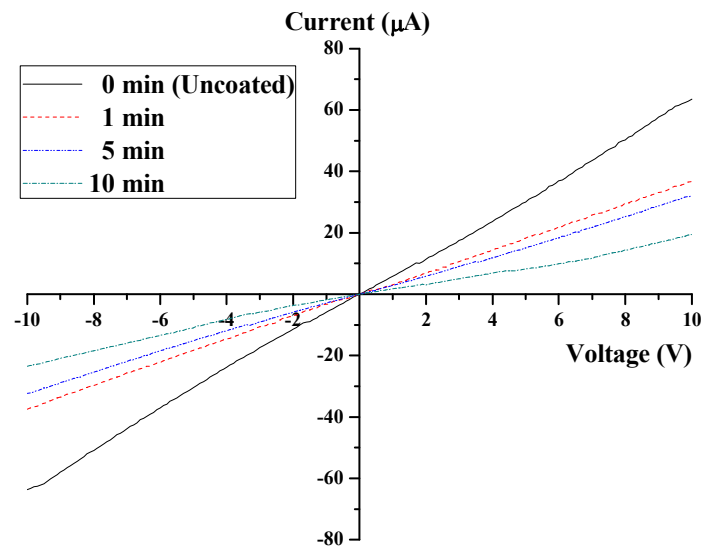

Figure 2, The I-V Characteristic of Al-Doped ZnO Nanorod Arrays Prepared at 50 min After Being Coated With Intrinsic ZnO Using RF Magnetron Sputtering at Deposition Times of 1, 5, and 10 $\min$.

The photocurrent measurement spectra of the Al-doped $\mathrm{ZnO}$ nanorod arrays deposited with intrinsic $\mathrm{ZnO}$ for 1, 5, and $10 \mathrm{~min}$ are shown in Figure 3. The results show that the photocurrent of the nanorod arrays decreased for longer depositions of intrinsic $\mathrm{ZnO}$ coatings. The photocurrent (dark current) of the Al-doped $\mathrm{ZnO}$ nanorods that were deposited with intrinsic $\mathrm{ZnO}$ at deposition times of 0 (uncoated), 1,5 , and $10 \mathrm{~min}$ are $2.39 \times 10^{-4}\left(2.26 \times 10^{-5}\right), 1.42 \times 10-4\left(7.50 \times 10^{-6}\right), 1.03$ $\times 10^{-4}\left(8.53 \times 10^{-6}\right)$ and $6.69 \times 10-5\left(5.53 \times 10^{-6}\right) \mathrm{A}$, respectively. From the photocurrent spectra, the responsivity of the sensors was estimated using following equation [11]:

$$
R=\frac{I_{p h}-I_{d a r k}}{P_{o p}},
$$

where $I_{p h}$ is the photocurrent, $I_{d a r k}$ is the dark current, and $P_{o p}$ is the optical power of the UV source. The responsivity of the sensors also decreased with $\mathrm{ZnO}$ deposition coating times, with values of $4.81,3.00,2.10$, and $1.37 \mathrm{~A} / \mathrm{W}$ after 0 (uncoated), 1, 5, and $10 \mathrm{~min}$ coatings, respectively. The results show that the responsivity decreases with intrinsic $\mathrm{ZnO}$ coatings due to an increase in the resistance of the nanorod arrays. However, the sensitivity of the devices improved with sputtered, intrinsic $\mathrm{ZnO}$ coatings. The sensitivity of the sensors, defined as the photocurrent-to- 
dark-current ratio, are 10.6, 19.0, 12.0 and 12.1 for Al-doped $\mathrm{ZnO}$ nanorod arrays coated with sputtered intrinsic $\mathrm{ZnO}$ at deposition time of 0 (uncoated), 1, 5, and $10 \mathrm{~min}$.

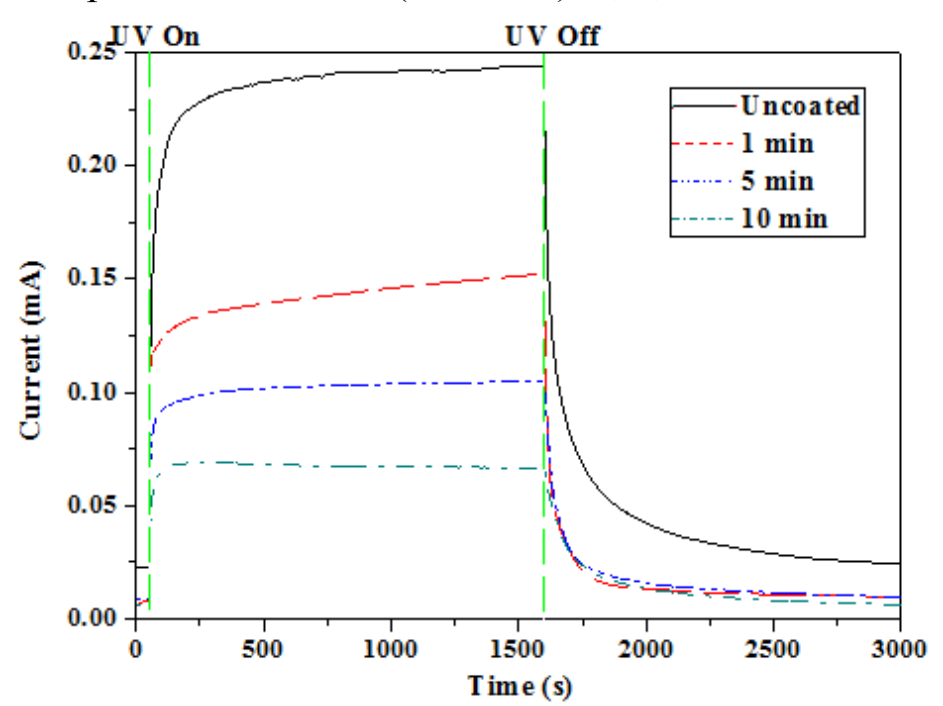

Figure 3, Photoresponse Spectra of the UV Photoconductive Sensor Using Al-Doped ZnO Nanorod Arrays Prepared at an Immersion Time of $50 \mathrm{~min}$ and Coated With Intrinsic ZnO Layer at Different Deposition Times Under UV Illumination (365 nm, $750 \mu \mathrm{W} / \mathrm{cm} 2)$ and a $10 \mathrm{~V}$ Bias.

The rise (decay) time constants of the sensor were calculated from the photocurrent spectra using the following equations:

$$
\begin{aligned}
& I=I_{0}\left[1-\exp \left(-\frac{t}{\tau_{r}}\right)\right]: \text { rise process with UV illumination on } \\
& I=I_{0} \exp \left(-\frac{t}{\tau_{d}}\right) \quad: \text { decay process with UV illumination off. }
\end{aligned}
$$

Here, $I$ is the magnitude of the current, $I_{0}$ is the saturated photocurrent, $t$ is the time, $\tau_{r}$ is the rise time constant and $\tau_{d}$ is the decay time constant. It was found that the rise (decay) time constants of the sensors were 10 (26), 4 (15), 7 (20), and 7 (40) s after $\mathrm{ZnO}$ coatings made for 0 (uncoated), 1, 5 , and $10 \mathrm{~min}$, respectively. Interestingly, these findings show that these rise time constants are lower than those of uncoated Al-doped $\mathrm{ZnO}$ nanorod arrays, suggesting that the intrinsic $\mathrm{ZnO}$ layer plays an important role in producing a low-conductivity barrier that controls electron flow when switched on and off under UV light. However, we also observed that the increase in deposition time resulted in thicker intrinsic $\mathrm{ZnO}$ coatings on the Al-doped $\mathrm{ZnO}$ nanorod arrays. For these samples, the rise (decay) time constants increased. This condition could be attributed to defects generated by the intrinsic layers, which trap carriers and increase the response time of the UV sensors.

\section{Conclusion}

The UV photoconductive sensors were successfully fabricated using intrinsic $\mathrm{ZnO}$ decorated, Al-doped $\mathrm{ZnO}$ nanorod arrays. FESEM images reveal that the morphology of Al-doped $\mathrm{ZnO}$ nanorod arrays were modified after intrinsic $\mathrm{ZnO}$ coatings. The I-V measurement indicates that the resistance of the sensors increased after coating process at longer deposition times. By sputtered coating with intrinsic $\mathrm{ZnO}$, we observed that sensitivity and response time of the sensor were improved. The results indicate that performance of the Al-doped $\mathrm{ZnO}$ nanorod array-based UV photoconductive sensor could be modulated by intrinsic $\mathrm{ZnO}$ layer coating on the nanorod surface, which may controls the electron flow when switched on and off under UV light. 


\section{Acknowledgement}

This work was supported by grant no. RAGS/2013/UITM/TK02/1 (600-RMI/RAGS 5/3 (52/2013)) and RACE/F2/TK2/UITM/9 (600-RMI/RACE 16/6/2 (9/2013)) from the Ministry of Education Malaysia. The authors also would like to thank the Research Management Institute (RMI) of UiTM and the Ministry of Higher Education of Malaysia for their financial support of this research.

\section{References}

[1] X. Fang, Y. Li, S. Zhang, L. Bai, N. Yuan and J. Ding, The dye adsorption optimization of $\mathrm{ZnO}$ nanorod-based dye-sensitized solar cells, Solar Energy 105 (2014) 14-19

[2] Q. Zhao, Y. Zeng, Y. Sui, W. Zhang and G. Zou, Development of microstructure sensor based on hierarchically 2-fold $\mathrm{ZnO}$ nanorod arrays on hydrotalcite-like ZnAlCO3 nanosheets, Sensors and Actuators B: Chemical 194 (2014) 206-212

[3] M. H. Mamat, N. N. Hafizah and M. Rusop, Fabrication of thin, dense and small-diameter zinc oxide nanorod array-based ultraviolet photoconductive sensors with high sensitivity by catalyst-free radio frequency magnetron sputtering, Materials Letters 93 (2013) 215-218

[4] M.-Y. Chuang, H.-C. Yu, Y.-K. Su, C.-H. Hsiao, T.-H. Kao, C.-S. Huang, Y.-C. Huang, J.J. Tsai and S.-L. Wu, Density-controlled and seedless growth of laterally bridged $\mathrm{ZnO}$ nanorod for UV photodetector applications, Sensors and Actuators B: Chemical 202 (2014) 810-819

[5] S. Ameen, M. S. Akhtar, H.-K. Seo and H.-S. Shin, Deployment of aligned ZnO nanorod with distinctive porous morphology: Potential scaffold for the detection of p-nitrophenylamine, Applied Catalysis A: General 470 (2014) 271-277

[6] M. H. Mamat, M. I. Che Khalin, N. N. H. Nik Mohammad, Z. Khusaimi, N. D. Md Sin, S. S. Shariffudin, M. Mohamed Zahidi and M. R. Mahmood, Effects of Annealing Environments on the Solution-Grown, Aligned Aluminium-Doped Zinc Oxide Nanorod-Array-Based Ultraviolet Photoconductive Sensor, Journal of Nanomaterials 2012 (2012) 15

[7] M. H. Mamat, M. F. Malek, N. N. Hafizah, Z. Khusaimi, M. Z. Musa and M. Rusop, Fabrication of an ultraviolet photoconductive sensor using novel nanostructured, nanoholeenhanced, aligned aluminium-doped zinc oxide nanorod arrays at low immersion times, Sensors and Actuators B: Chemical 195 (2014) 609-622

[8] K. Y. Ko, H. Kang, J. Park, B.-W. Min, H. S. Lee, S. Im, J. Y. Kang, J.-M. Myoung, J.-H. Jung, S.-H. Kim and H. Kim, $\mathrm{ZnO}$ homojunction core-shell nanorods ultraviolet photo-detecting diodes prepared by atomic layer deposition, Sensors and Actuators A: Physical 210 (2014) 197-204

[9] M. H. Mamat, Z. Khusaimi, M. M. Zahidi, A. B. Suriani, Y. M. Siran, S. A. M. Rejab, A. J. Asis, S. Tahiruddin, S. Abdullah and M. R. Mahmood, Controllable Growth of Vertically Aligned Aluminum-Doped Zinc Oxide Nanorod Arrays by Sonicated Sol-Gel Immersion Method depending on Precursor Solution Volumes, Japanese Journal of Applied Physics 50 (2011) 06GH04 [10] M. H. Mamat, M. Z. Sahdan, Z. Khusaimi, A. Z. Ahmed, S. Abdullah and M. Rusop, Influence of doping concentrations on the aluminum doped zinc oxide thin films properties for ultraviolet photoconductive sensor applications, Optical Materials 32 (2010) 696-699

[11] J. H. Jun, H. Seong, K. Cho, B.-M. Moon and S. Kim, Ultraviolet photodetectors based on $\mathrm{ZnO}$ nanoparticles, Ceramics International 35 (2009) 2797-2801 